\title{
Negative Differential Resistance Observation and a New Fitting Model for Electron Drift Velocity in GaN-Based Heterostructures
}

\author{
Gökhan Atmaca $^{\circledR}$, Polat Narin, Ece Kutlu, Timur Valerevich Malin, Vladimir G. Mansurov, \\ Konstantin Sergeevich Zhuravlev, Sefer Bora Lişesivdin, Senior Member, IEEE, \\ and Ekmel Özbay, Member, IEEE
}

\begin{abstract}
The aim of this paper is an investigation of electric field-dependent drift velocity characteristics for $\mathrm{Al}_{0.3} \mathrm{Ga}_{0.7} \mathrm{~N} / \mathrm{AIN} / \mathrm{GaN}$ heterostructures without and with in situ $\mathrm{Si}_{3} \mathrm{~N}_{4}$ passivation. The nanosecond-pulsed currentvoltage $(I-V)$ measurements were performed using a 20-ns applied pulse. Electron drift velocity depending on the electric field was obtained from the $I-V$ measurements. These measurements show that a reduction in peak electron velocity from $2.01 \times 10^{7}$ to $1.39 \times 10^{7} \mathrm{~cm} / \mathrm{s}$ after in situ $\mathrm{Si}_{3} \mathrm{~N}_{4}$ passivation. Also, negative differential resistance regime was observed which begins at lower fields with the implementation of in situ $\mathrm{Si}_{3} \mathrm{~N}_{4}$ passivation. In our samples, the electric field dependence of drift velocity was measured over $400 \mathrm{kV} / \mathrm{cm}$ due to smaller sample lengths. Then, a wellknown fitting model was fitted to our experimental results. This fitting model was improved in order to provide an adequate description of the field dependence of drift velocity. It gives reasonable agreement with the experimental drift velocity data up to $475 \mathrm{kV} / \mathrm{cm}$ of the electric field and could be used in the device simulators.
\end{abstract}

Manuscript received September 3, 2017; revised November 24, 2017 and December 26, 2017; accepted January 15, 2018. Date of publication February 8, 2018; date of current version February 22, 2018. This work was supported in part by the International Bilateral Research Project between RFBR and TUBITAK under Project 113F364, in part by the Projects DPT-HAMIT, DPT-FOTON, NATO-SET-193, and TUBITAK through the Nanotechnology Research Center, Bilkent University, Turkey under Project 113E331, Project 109A015, and Project 109E301, in part by the Distinguished Young Scientist Award of Turkish Academy of Sciences (TUBA-GEBIP 2016), and in part by the Ministry of Education and Science of the Russian Federation with the unique identifier of the project RFMEFI57717X0250. The work of E. Ozbay was supported by the Turkish Academy of Sciences. The review of this paper was arranged by Editor K. Kalna. (Corresponding author: Gökhan Atmaca.)

G. Atmaca, P. Narin, E. Kutlu, and S. B. Lişesivdin are with the Lisesivdin Research Group, Faculty of Science, Department of Physics, Gazi University, 06500 Ankara, Turkey (e-mail: gokhanatmaca @ kuark.org).

T. V. Malin and V. G. Mansurov are with the Rzhanov Institute of Semiconductor Physics, Siberian Branch of Russian Academy of Sciences, 630090 Novosibirsk, Russia.

K. S. Zhuravlev is with the Rzhanov Institute of Semiconductor Physics, Siberian Branch of Russian Academy of Sciences, 630090 Novosibirsk, Russia, and also with the Department of Physics, Novosibirsk State University, 630090 Novosibirsk, Russia.

E. Özbay is with the Nanotechnology Research Center, Bilkent University, 06800 Ankara, Turkey, with the Physics Department, Bilkent University, 06800 Ankara, Turkey, and also with the Electrical and Electronics Engineering, Bilkent University, 06800 Ankara, Turkey.

Color versions of one or more of the figures in this paper are available online at http://ieeexplore.ieee.org.

Digital Object Identifier 10.1109/TED.2018.2796501
Index Terms-2-dimensional electron gas (2DEG), AIGaN, drift velocity, gallium nitride (GaN), negative differential resistivity (NDR), SiN passivation.

\section{INTRODUCTION}

$\mathbf{G}$ ALLIUM nitride (GaN)-based HEMTs are highly used devices in many applications such as radar communication, amplifiers, and satellite communication [1]-[3]. Because $\mathrm{GaN}$ has material properties such as wide direct bandgap, high breakdown field, high electron drift velocity, and high thermal conductivity that are important for such these high-power and high-frequency demanding device applications [4]-[6]. In AlGaN/GaN heterostructures, the spontaneous and piezoelectric polarization between $\mathrm{AlGaN}$ and $\mathrm{GaN}$ leads to significant sheet carrier density up to a few $10^{13} \mathrm{~cm}^{-2}$ at the interface [7]. To increase of sheet carrier density and output current of a device, $\mathrm{Si}_{3} \mathrm{~N}_{4}$ surface passivation has been used in various studies [8]-[10]. Besides this purpose, it provides larger breakdown voltage due to its dielectric properties [11], [12]. Therefore, $\mathrm{Si}_{3} \mathrm{~N}_{4}$ surface passivation can be used to provide the experimental data of drift velocity for higher electric fields in comparison samples without passivation [12].

Electron drift velocity $v_{d}$ is one of the important material parameters to evaluate the suitability of a semiconductor at high-voltage operation. Also, the cutoff frequency, which is the most widely used parameter as a figure of merit, depends on the electron drift velocity [13], [14]. Therefore, the determination of the electron velocity is important in the description of maximum frequency operation for a transistor structure. Experimental and theoretical studies of highfield electron drift velocity in bulk GaN and AlGaN/GaN heterostructures were reported in many papers [12], [15]-[23]. For wurtzite bulk GaN, Wraback et al. [15] reported experimental results of drift velocity-electric field characteristics up to $350 \mathrm{kV} / \mathrm{cm}$ of electric field. Then, the experimental results of drift velocity-electric field $\left(v_{d}-E\right)$ characteristics for an $\mathrm{AlGaN} / \mathrm{GaN}$ heterostructure have been obtained up to $140 \mathrm{kV} / \mathrm{cm}$ of the electric field by Ardaravičius et al. [16]. They found a peak drift velocity $v_{\text {peak }}$ value of $2 \times 10^{7} \mathrm{~cm} / \mathrm{s}$ at $140 \mathrm{kV} / \mathrm{cm}$. In 2005, Barker et al. [12] reported experimental measurements up to $150 \mathrm{kV} / \mathrm{cm}$ for two different 
contact structures in the same sample. Also, these experimental results compared with Monte Carlo simulations reported by $\mathrm{Yu}$ and Brennan [17] and they found a good agreement. In another a paper, the reached applied electric field for an $\mathrm{Al}_{0.33} \mathrm{Ga}_{0.67} \mathrm{~N} / \mathrm{AlN} / \mathrm{GaN}$ heterostructure was reported as $200 \mathrm{kV} / \mathrm{cm}$ [20]. In spite of Monte Carlo simulations assert a negative differential resistance (NDR) phenomenon for $v_{d}-E$ characteristics in this field range, it has been not observed exactly in the previous experimental studies [21].

NDR phenomenon was first observed in III-V semiconductors by Gunn [24]. When applied electric field exceeds a critical value, the current or drift velocity of bulk or heterostructure material is tend to decrease. This is called as NDR, and it is thought originated that electrons with high kinetic energy can transit from low energy band to upper band, which has larger electron effective mass, after the critical field in several studies [25], [26]. Direct evidence of NDR in bulk GaN was first reported by Huang et al. [26]. To our knowledge, it is not observed in drift velocity-electric field characteristics of GaN-based HEMT structures until now [20]-[23]. However, there are some papers reported that GaN-based diode structures exhibit NDR in $I-V$ curves [24], [25], [27]. Exactly obtaining of the NDR effect is important to better understand device physics at high fields and in the improvement of NDR device implementations [25]. To reveal $v_{d}-E$ characteristics and observe NDR at higher fields, the applied electric field in these heterostructures must be higher than $150 \mathrm{kV} / \mathrm{cm}$ according to the Monte Carlo simulations that predict the NDR effect [17]-[20]. To reach higher fields, sample sizes can be reduced and $\mathrm{Si}_{3} \mathrm{~N}_{4}$ passivation can be used [12]. To our knowledge, in this paper, it is first time reported the experimental observation of NDR in $v_{d}-E$ characteristics of GaN-based HEMT structures.

In this paper, we presented the experimental electric field dependence of the drift velocity of AlGaN/AlN/GaN heterostructures with and without in situ $\mathrm{Si}_{3} \mathrm{~N}_{4}$ passivation layer in the wide range of electric field up to $475 \mathrm{kV} / \mathrm{cm}$. The electric field dependences of these heterostructures were measured by the nanosecond-pulsed current-voltage $(I-V)$ measurements. These experimental results revealed NDR phenomenon and behavior of drift velocity in high fields for an $\mathrm{AlGaN} / \mathrm{AlN} / \mathrm{GaN}$ heterostructure. Then, the experimental $v_{d}-E$ characteristics were fitted to a well-known fitting model proposed by Farahmand et al. [19] and obtained fitting parameters were discussed.

\section{EXPERIMENT}

In this paper, the measurement results of the drift velocity at high electric fields in AlGaN/AlN/GaN heterostructures with and without $\mathrm{Si}_{3} \mathrm{~N}_{4}$ surface passivation layer are presented. The drift velocity as a function of the electric field was determined using nanosecond-pulsed voltage technique. It is a widely used technique to obtain $v_{d}-E$ characteristics [12], [20]-[23]. In 2002, nanosecond-pulsed voltage technique was first time used to measure drift velocity-electric field in steady state AlGaN/GaN HEMT structure by Balkan et al. [28]. In this technique, the electric field dependence of electron drift

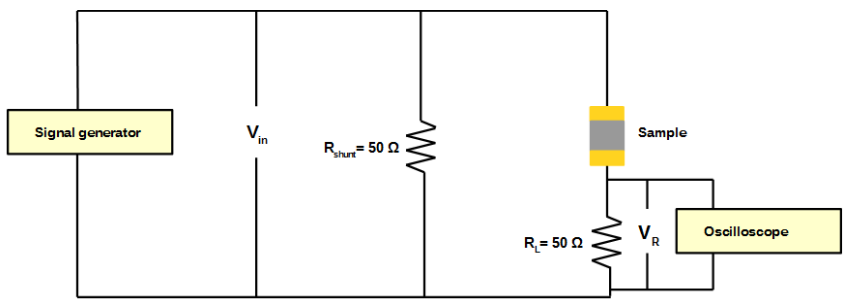

Fig. 1. Electron drift velocity measurement setup.

velocity is extracted from the dependence of current density on electric field measured using the nanosecond-pulsed $I-V$ measurements. In these measurements, high-voltage signal generator is used and the low pulsewidth or low pulse duration is required to avoid Joule heating [14], [22]. With nanosecondpulsed voltage technique, the current density of investigated sample measured by applying a potential to the sample. The drift velocity can be calculated from measured the current that flows through the sample

$$
v_{d}=\frac{I}{\mathrm{nqwt}}
$$

where $I$ is the current through the sample, and $w$ and $t$ are width and thickness of the sample, respectively. $n$ is the carrier density of 2-dimensional electron gas (2DEG) and $q$ is electron charge.

We fabricated two samples that $951 \mathrm{~N}$ and $951 \mathrm{Y}$ are AlGaN/AlN/GaN heterostructures without and with in situ $\mathrm{Si}_{3} \mathrm{~N}_{4}$ passivation layer, respectively. The $\mathrm{Al}_{0.3} \mathrm{Ga}_{0.7} \mathrm{~N} /$ AlN/GaN heterostructures were grown in a Riber 32 molecular beam epitaxy (MBE) system. The heterostructures consisted of $25-\mathrm{nm} \mathrm{Al}_{0.3} \mathrm{Ga}_{0.7} \mathrm{~N}$ barrier layer with covered 2-nm GaN cap layer, 1-nm AlN interlayer, 1.5- $\mu \mathrm{m} \mathrm{GaN} \mathrm{buffer,} \mathrm{100-nm}$ AlN (1 nm)/GaN (1 nm) superlattice layer, and 250-nm AlN nucleation layer on a (001)-oriented $400-\mu$ m-thick sapphire substrate. For a $951 \mathrm{Y}$ sample, the $\mathrm{Si}_{3} \mathrm{~N}_{4}$ dielectric film was deposited at $850{ }^{\circ} \mathrm{C}$ immediately following the $\mathrm{GaN}$ cap layer growth in the same MBE chamber. The ohmic contacts, $\mathrm{Ti} / \mathrm{Al} / \mathrm{Ni} / \mathrm{Au}(15 / 40 / 40 / 70 \mathrm{~nm})$ were deposited by e-beam evaporation and annealed in nitrogen for $30 \mathrm{~s}$ at $850^{\circ} \mathrm{C}$. Higher electric fields can be induced as the length of the sample is reduced. Owing to these small sample sizes, it is expected to obtain higher electric fields in comparison that of [12].

To determine the high-field transport properties, the nanosecond-pulsed $I-V$ measurements have been performed using simple-bar-shaped samples of $l=4 \mu \mathrm{m}$ and $w=1 \mu \mathrm{m}$ at $77 \mathrm{~K}$. The voltage pulses of $20 \mathrm{~ns}$ duration with a duty cycle of $0.005 \%$ were applied along the length of the sample up to a maximum electric field of $E=475 \mathrm{kV} / \mathrm{cm}$ with Avtech AVIR3 -B high-voltage pulse generator in a homemade $\mathrm{LN}_{2}$-cooled sample holder. Applied voltage and current across the $50-\Omega$ load resistor $R_{L}$ connected in series with the sample were measured using a 50- $\Omega$ input impedance high-speed digital oscilloscope. Measurement setup is shown in Fig. 1. From the pulsed $I-V$ measurements, electron drift velocity as a function of the electric field was obtained with the assumption that the 2DEG electron density within the heterostructure 
TABLE

Hall Effect Measurements Results of the Samples [30]

\begin{tabular}{|l|l|l|l|}
\hline Sample & Passivation & $\begin{array}{l}\text { Sheet carrier density } \\
\text { at } 77 \mathbf{K}\left(\mathbf{c m}^{-2}\right)\end{array}$ & $\begin{array}{l}\text { 2DEG mobility at } \mathbf{7 7} \\
\mathbf{K}\left(\mathbf{c m}^{2} / \mathbf{V s}\right)\end{array}$ \\
\hline $951 \mathrm{~N}$ & No & $1.21 \times 10^{13}$ & 2385 \\
\hline $951 \mathrm{Y}$ & Yes & $1.31 \times 10^{13}$ & 2244 \\
\hline
\end{tabular}

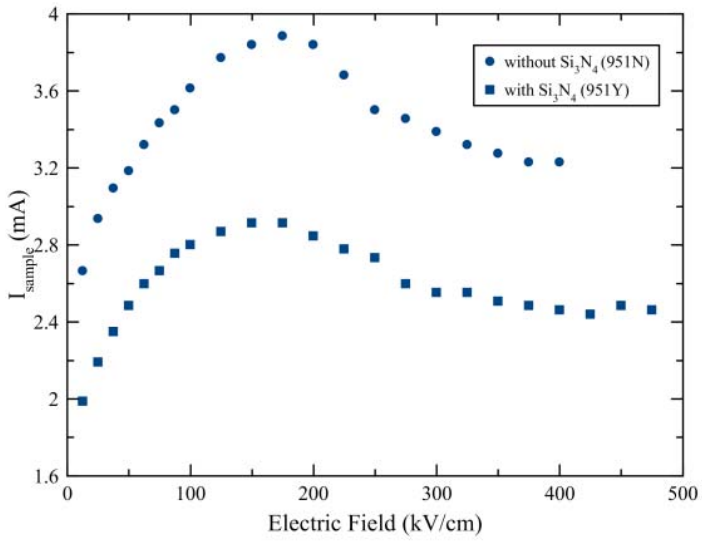

Fig. 2. Sample current versus electric field in AIGaN/AIN/GaN heterostructures with $(951 \mathrm{Y})$ and without $(951 \mathrm{~N}) \mathrm{Si}_{3} \mathrm{~N}_{4}$ passivation layer.

remains constant within the applied electric field ranges [29]. The results of the Hall effect measurements of the samples are given in Table I. The measured sheet carrier densities of heterostructures without and with in situ $\mathrm{Si}_{3} \mathrm{~N}_{4}$ passivation layer are $1.21 \times 10^{13}$ and $1.31 \times 10^{13} \mathrm{~cm}^{-2}$, respectively [30].

\section{Results And Discussion}

Sample current-electric field curves of the AlGaN/AlN/GaN heterostructures with and without $\mathrm{Si}_{3} \mathrm{~N}_{4}$ passivation layer shown in Fig. 2. In both of heterostructures, the curve at low electric fields gives a linear relation obeying ohm's law [31]. Then, around $150 \mathrm{kV} / \mathrm{cm}$, the sample current has a peak point. With further increasing the electric field, the sample current is decreased. This behavior obeys with NDR phenomenon [25], [26]. In our case, NDR effect in $\mathrm{AlGaN} / \mathrm{GaN}$ heterostructures is observed owing to smaller sample dimensions. On the other hand, the nanosecond pulses in the range of 1-200 ns were used to minimize self-heating effect in many studies [12], [16], [20]-[23]. In this paper, our signal generator Avtech AVIR-3-B can produce in the range of $10-200 \mathrm{~ns}$ pulse and we observed square voltage pulse shape in $20 \mathrm{~ns}$ as a minimum point. At high electric fields, the self-heating effect could imply considerable effects on current-electric field characteristics even a few nanosecond pulsewidths was used [16]. According to these studies, a reduction in current values due to self-heating can be expected in our case. However, Ardaravičius et al. [16] stated that channel self-heating causes the current to saturate if pulses longer than $20 \mathrm{~ns}$ were applied. In our case, no saturation in the current was observed. In addition to this, observed negative slope in the currentelectric field characteristics is not mainly caused by the selfheating effect at high electric fields [32]. Moreover, to consider

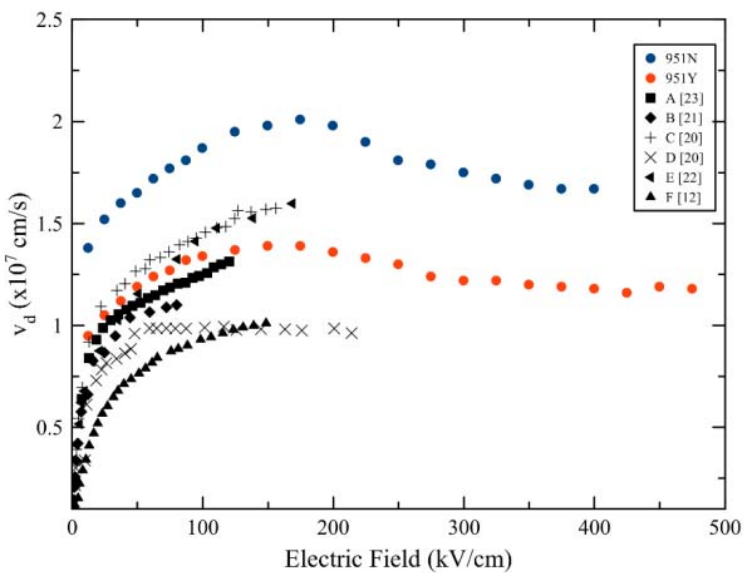

Fig. 3. Experimental results of electron drift velocity as a function of electric field for $\mathrm{Al}_{0.3} \mathrm{Ga}_{0.7} \mathrm{~N} / \mathrm{AIN} / \mathrm{GaN}$ heterostructures without $(951 \mathrm{~N})$ and with (951Y) in situ $\mathrm{Si}_{3} \mathrm{~N}_{4}$ passivation and $\mathrm{AlGaN} / \mathrm{GaN}$ heterostructures reported in [12] and [20]-[23]. A summary of all these heterostructures is given in Table II.

whether self-heating has an influence on current-electric field characteristics at high electric fields, we tried to calculate the hot-phonon lifetime in our samples. Because, the hotphonon effects are weaker when the lifetime is shorter and Liberis et al. [33] and Barker et al. [34] have shown that hotphonon effects may not be very serious and the suggested hot phonon lifetime is less than 0.3 ps. In our samples, it is estimated that the hot-phonon lifetime in our samples changes between 0.01 and $0.13 \mathrm{ps}$ at high fields using a simple expression suggested by several studies to calculate hot phonon lifetime [35], [36]. Further studies including detailed investigations using Monte Carlo simulations on these results are needed to investigate possibility of the self-heating effect and reveal high-field transport properties.

Fig. 3 shows an electric field dependence of drift velocity of $\mathrm{AlGaN} / \mathrm{AlN} / \mathrm{GaN}$ heterostructures without and with in situ $\mathrm{Si}_{3} \mathrm{~N}_{4}$ passivation layer. These measurements of this dependence are taken up to 400 and $475 \mathrm{kV} / \mathrm{cm}$ field owing to smaller lengths of samples and protection maintained by the $\mathrm{Si}_{3} \mathrm{~N}_{4}$ surface passivation layer. The dependence of the drift velocity on the electric field is almost linear at low fields. However, after drift velocity reached its peak value, it is decreased as electric field increases. This behavior is clear evidence of NDR in $v_{d}-E$ characteristics [37]. In this case, 2DEG electrons in the lowest $\Gamma$ minimum point accelerate under high fields and gain enough energy to transfer to $\mathrm{L}$ valley minima which is $0.90 \mathrm{eV}$ above conduction band minimum [38]-[42]. Therefore, when they reached peak velocity, it begins the transfer from $\Gamma$ valley to $L$ satellite valley. In the $L$ satellite valley, drift velocity decreases because of 2DEG electrons have higher effective mass [14], [18]. This is called as the transferred-electron effect in $\mathrm{GaN}$ and it is experimentally confirmed for bulk GaN [26].

From Fig. 3, it is found that the maximum peak velocity is $2.01 \times 10^{7} \mathrm{~cm} / \mathrm{s}$ and the peak electric field where peak electron velocity is $174 \mathrm{kV} / \mathrm{cm}$ for unpassivated heterostructure. For the passivated heterostructure, while the $v_{\text {peak }}$ is $1.39 \times 10^{7} \mathrm{~cm} / \mathrm{s}$, the peak electric field is around $149 \mathrm{kV} / \mathrm{cm}$. The value of $v_{\text {peak }}$ 
is decreased from $2.01 \times 10^{7}$ to $1.39 \times 10^{7} \mathrm{~cm} / \mathrm{s}$ after passivation. Similarly, the electric field where $v_{\text {peak }}$ is decreased from 174 to $149 \mathrm{kV} / \mathrm{cm}$ after passivation. In GaN-based heterostructures, the $v_{\text {peak }}$ occurs in very large fields which resulted in a higher effective mass and higher density of states when compared with GaAs [18]. After passivation, this decrement in the value of $v_{\text {peak }}$ can be explained with the increment in the sheet carrier density because of electron velocity depends on sheet carrier density. The origin of high 2DEG density in an $\mathrm{AlGaN} / \mathrm{GaN}$ heterostructure is polarization, and therefore, polarization-induced charges scatter carriers and limit their mobility [43]. Sheet carrier density in the studied sample is increased from $1.21 \times 10^{13}$ to $1.31 \times 10^{13} \mathrm{~cm}^{-2}$ after passivation. However, this increment in sheet carrier density is limited. Moreover, it may not cause a significant change in the peak electric field. On the other hand, it is well known that $\mathrm{Si}_{3} \mathrm{~N}_{4}$ passivation layer alters the density of states and the trap density at the surface of heterostructures [9], [42], [44]. Actually, NDR effect depends on the density of states and trap density at the surface [45]-[47]. Therefore, the decrement in the peak electric field is observed after the passivation may be caused by a reduction in free surface states and surface trap density.

A comparison between our results and experimental results of drift velocity as a function of the electric field measured in various previous studies at $300 \mathrm{~K}$ for $\mathrm{AlGaN} / \mathrm{GaN}$ heterostructures is also shown in Fig. 3. In Fig. 3, A, B, C, D, E, and $\mathrm{F}$ implies that $v_{d}-E$ characteristics of various $\mathrm{AlGaN} / \mathrm{GaN}$ heterostructures extracted using nanosecond-pulsed $I-V$ measurements at $300 \mathrm{~K}$ in [12] and [20]-[23]. Characteristics of sample A with sample dimensions of $20 \times 20 \mu \mathrm{m}$ was measured by Guo et al. [23] using an 80-ns pulsewidth and saturation velocity is $1.30 \times 10^{7} \mathrm{~cm} / \mathrm{s}$ at $120 \mathrm{kV} / \mathrm{cm}$. Danilchenko et al. [21] reported that measured saturation velocity of an $\mathrm{AlGaN} / \mathrm{GaN}$ heterostructure (sample B) with $100 \times 10 \mu \mathrm{m}$ using 30-ns pulsewidth is $1.1 \times 10^{7} \mathrm{~cm} / \mathrm{s}$ at $80 \mathrm{kV} / \mathrm{cm}$. Characteristics of sample C, sample D, and sample E were measured by Ardaravičius et al. [20], [22] in different studies. Measured saturation or peak drift velocities of these samples are $1.50 \times 10^{7} \mathrm{~cm} / \mathrm{s}$ at $156 \mathrm{kV} / \mathrm{cm}, 1 \times 10^{7} \mathrm{~cm} / \mathrm{s}$ at $210 \mathrm{kV} / \mathrm{cm}$, and $1.34 \times 10^{7} \mathrm{~cm} / \mathrm{s}$ at $162 \mathrm{kV} / \mathrm{cm}$, respectively. Barker et al. [12] measured $v_{d}-E$ characteristics of an $\mathrm{Al}_{0.25} \mathrm{Ga}_{0.75} \mathrm{~N} / \mathrm{GaN}$ heterostructure with $10 \times 3 \mu \mathrm{m}$ sample dimensions using a $200-n s$ pulsewidth. Saturation velocity of sample $\mathrm{F}$ is around $1 \times 10^{7} \mathrm{~cm} / \mathrm{s}$ at $150 \mathrm{kV} / \mathrm{cm}$. According to Fig. 3, the electric field dependence of drift velocity of specially $951 \mathrm{Y}$ is agreement with the experimental data previously obtained by [20]-[23] for low fields. A summary of all these heterostructures is given in Table II.

Table II compares the applied maximum electric field, the peak electric field, and the $v_{\text {sat }}$ or $v_{\text {peak }}$ values obtained using the nanosecond-pulsed $I-V$ measurements in $\mathrm{AlGaN} / \mathrm{GaN}$ heterostructures for various sample dimensions. In Table II, the applied maximum electric field is increased by reducing the sample dimensions. Especially in this paper, for the $l=4 \mu \mathrm{m}$, it is reached up to 400 and $475 \mathrm{kV} / \mathrm{cm}$ obtaining larger electric fields with smaller voltages. To obtain the applied maximum electric field of $150 \mathrm{kV} / \mathrm{cm}$ for a sample
TABLE II

Applied Maximum ELECTRic Field $\left(F_{\text {MAX }}\right)$, AND the $v_{\text {SAT }}$ OR $V_{\text {PEAK }}$ VAlues OBtained USING THE NANOSECOND-PULSED $I-V$ MEAsurements in AlGaN/GaN HEterostructures for Various SAMPLE DIMENSIONS [12], [20]-[23]

\begin{tabular}{|c|c|c|c|c|c|}
\hline Sample & Sample type & $\begin{array}{c}\mathbf{w x l} \\
(\mu \mathrm{m})\end{array}$ & $\mathrm{Si}_{3} \mathrm{~N}_{4}$ & $\begin{array}{c}F_{\max } \\
(\mathrm{kV} / \mathrm{cm})\end{array}$ & $\begin{array}{c}v_{\text {sat }} \text { or } \\
v_{\text {peak }} \\
(\mathbf{x 1 0} \\
\mathrm{cm} / \mathrm{s})\end{array}$ \\
\hline $\mathrm{A}[23]$ & $\mathrm{Al}_{0.24} \mathrm{Ga}_{0.76} \mathrm{~N} / \mathrm{GaN}$ & $20 \times 20$ & Yes & 120 & 1.30 \\
\hline $\mathrm{B}[21]$ & $\mathrm{Al}_{0.33} \mathrm{Ga}_{0.67} \mathrm{~N} / \mathrm{GaN}$ & $100 \times 10$ & Yes & 80 & 1.10 \\
\hline $\mathrm{C}[20]$ & $\mathrm{Al}_{0.15} \mathrm{Ga}_{0.85} \mathrm{~N} / \mathrm{GaN}$ & $120 \times 7$ & Yes & 156 & 1.50 \\
\hline $\mathrm{D}[20]$ & $\begin{array}{c}\mathrm{Al}_{0.33} \mathrm{Ga}_{0.67} \mathrm{~N} / \mathrm{AlN} / \\
\mathrm{GaN}\end{array}$ & $100 \times 5$ & Yes & 210 & 1.00 \\
\hline $\mathrm{E}[22]$ & $\begin{array}{c}\mathrm{Al}_{0.33} \mathrm{Ga}_{0.67} \mathrm{~N} / \mathrm{AlN} / \\
\mathrm{Al}_{0.1} \mathrm{Ga}_{0.9} \mathrm{~N} / \mathrm{GaN}\end{array}$ & $260 \times 4$ & Yes & 162 & 1.34 \\
\hline $\mathrm{F}[12]$ & $\begin{array}{c}\mathrm{Al}_{0.25} \mathrm{Ga}_{0.75} \mathrm{~N} / \mathrm{AlN} / \\
\mathrm{GaN}\end{array}$ & $10 \times 3$ & Yes & 150 & 1.00 \\
\hline $951 \mathrm{~N}$ & $\begin{array}{c}\mathrm{Al}_{0.3} \mathrm{Ga}_{0.7} \mathrm{~N} / \mathrm{AlN} / \mathrm{G} \\
\mathrm{aN}\end{array}$ & $1 \times 4$ & No & 400 & 2.01 \\
\hline $951 \mathrm{Y}$ & $\begin{array}{c}\mathrm{Al}_{0.3} \mathrm{Ga}_{0.7} \mathrm{~N} / \mathrm{AlN} / \mathrm{G} \\
\mathrm{aN}\end{array}$ & $1 \times 4$ & Yes & 475 & 1.39 \\
\hline
\end{tabular}

with $l=10 \mu \mathrm{m}$, the applied voltage to sample should be $150 \mathrm{~V}$. In the $4 \mu \mathrm{m}$ case, the applied voltage of $150 \mathrm{~V}$ is corresponding to $375 \mathrm{kV} / \mathrm{cm}$. So, this Table II and the findings in this paper present that the drift velocity measurement investigations of GaN-based heterostructures with smaller sample lengths is important to reveal the NDR effect and drift velocity characteristics in high fields.

Analytical models describing $v_{d}-E$ characteristics have been widely used in device simulators [37], [48], [49]. With the relation between mobility and drift velocity, $v_{d}=\mu E$, the analytical models are compatible with the experimental measurements of drift velocity play important role in development of mobility models used in device simulations [17], [19], [37]. Therefore, improvement of analytical models describing $v_{d}-E$ characteristics is essential to make more reliable device design for device simulators. Mobility model developed by Caughey and Thomas [50] is a widely used empirical expression. The field dependence of drift velocity expression derived from the mobility model is not suited for modeling the drift velocity at high fields where NDR effect may be observed [37]. So, field-dependent mobility models due to the absence of experimental data in high fields were developed relying on Monte Carlo simulations. Farahmand et al. [19] first reported a field-dependent mobility model of bulk GaN and then, Yu and Brennan [17] reported the same mobility model for an AlGaN/GaN heterostructure. While $\mathrm{AlGaN} / \mathrm{GaN}$ heterostructures in the previous experimental studies reached to $150 \mathrm{kV} / \mathrm{cm}$ as can be seen in Fig. 3, our samples reached over $400 \mathrm{kV} / \mathrm{cm}$. Therefore, this mobility model should compare with electric field dependence of drift velocity of our samples in the wide range of electric field up to $475 \mathrm{kV} / \mathrm{cm}$. Drift velocity-electric field expression extracted from this mobility model in [17] and [19] is given in the following:

$$
v(E)=\frac{\mu_{0} E+v_{\text {sat }}\left(E / E_{C}\right)^{n_{1}}}{1+n_{2}\left(E / E_{C}\right)^{n_{3}}+\left(E / E_{C}\right)^{n_{1}}}
$$




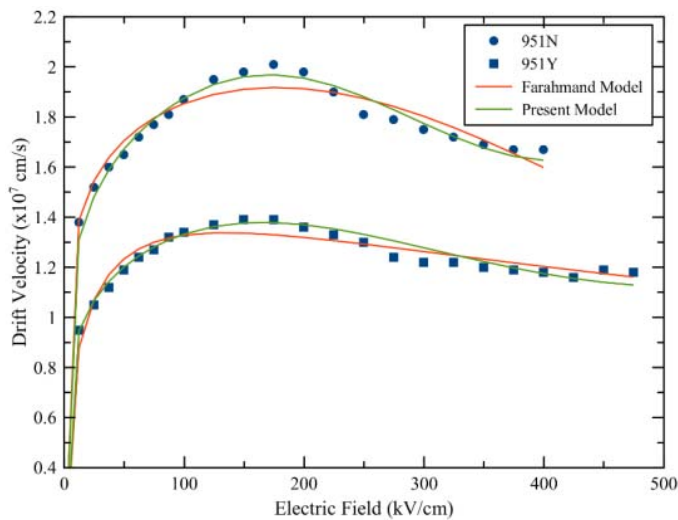

Fig. 4. Experimental results of electron drift velocity as a function of electric field in $\mathrm{Al}_{0.3} \mathrm{Ga}_{0.7} \mathrm{~N} / \mathrm{AIN} / \mathrm{GaN}$ heterostructures without (951N) and with (951Y) in situ $\mathrm{Si}_{3} \mathrm{~N}_{4}$ passivation and a comparison to mobility models. Red line represents the Farahmand model given in (2), and green line represents the derived expression given in (5).

TABLE III

Values of Fitting Parameters Extracted From the EXPERIMENTAL DATA OF AN $\mathrm{Al}_{0.3} \mathrm{Ga}_{0.7} \mathrm{~N} / \mathrm{AIN} / \mathrm{GaN}$ Heterostructure Without in situ $\mathrm{Si}_{3} \mathrm{~N}_{4}$ Passivation (951N)

\begin{tabular}{ccc}
\hline \hline Parameters & Farahmand Model & Present Model (Eq.5) \\
\hline $\boldsymbol{v}_{\text {sat }}\left(\boldsymbol{v}_{\text {peak }}\right)(\mathrm{cm} / \mathbf{s})$ & $4.01 \times 10^{7}$ & $2.06 \times 10^{7}$ \\
$\boldsymbol{E}_{\boldsymbol{C}}(\boldsymbol{k V} / \mathrm{cm})$ & 180.20 & 180.20 \\
$\boldsymbol{n}_{\boldsymbol{1}}$ & 0.24 & 0.17 \\
$\boldsymbol{n}_{\boldsymbol{2}}$ & 0.13 & -0.93 \\
$\boldsymbol{n}_{3}$ & 2.22 & - \\
$\boldsymbol{n}_{4}$ & - & 4.04 \\
$\boldsymbol{b}$ & - & 0.06 \\
\hline \hline
\end{tabular}

TABLE IV

Values of Fitting Parameters Extracted From the EXPERIMENTAL DATA OF AN $\mathrm{Al}_{0.3} \mathrm{Ga}_{0}{ }_{7} \mathrm{~N} / \mathrm{ALN} / \mathrm{GAN}$ Heterostructure With in situ $\mathrm{Si}_{3} \mathrm{~N}_{4}$ PASSIVATION (951Y)

\begin{tabular}{ccc}
\hline \hline Parameters & Farahmand Model & Present Model (Eq. 5) \\
\hline $\boldsymbol{v}_{\text {peak }}(\mathrm{cm} / \mathrm{s})$ & $4.01 \times 10^{7}$ & $1.44 \times 10^{7}$ \\
$\boldsymbol{E}_{\boldsymbol{C}}(\mathbf{k V} / \mathrm{cm})$ & 165.00 & 149.63 \\
$\boldsymbol{n}_{1}$ & 0.46 & 0.17 \\
$\boldsymbol{n}_{2}$ & 1.03 & -0.93 \\
$\boldsymbol{n}_{3}$ & 1.04 & - \\
$\boldsymbol{n}_{4}$ & - & 2.95 \\
$\boldsymbol{b}$ & - & 0.04 \\
\hline
\end{tabular}

where $\mu_{0}$ is low-field mobility and $v_{\text {sat }}$ is saturation velocity. $\mu_{0}$ values of $951 \mathrm{~N}$ and $951 \mathrm{Y}$ are used as 2385 and $2244 \mathrm{~cm}^{2} / \mathrm{V} \cdot \mathrm{s}$ from [30], respectively. $E_{C}, n_{1}, n_{2}$, and $n_{3}$ are adjustable fitting parameters. When this expression is fitted to the experimental data as it can be seen in Fig. 4, it seems like the expression describes to $v_{d}-E$ characteristics of our samples. However, according to Tables III and IV, $v_{\text {sat }}$ parameter value is $4.01 \times 10^{7} \mathrm{~cm} / \mathrm{s}$ as a fitting parameter. This value has no a counterpart in the experimental results. On the other hand, $v_{\text {sat }}$ found to be a misinterpreted parameter to describe the $v_{d}-E$ characteristics with an NDR behavior. The $v_{d}-E$ characteristics that included NDR effect exhibit a peak drift velocity rather than saturation velocity. Hence, a new expression which is consistent with experimental data obtained in this paper was derived from (2) as

$$
v(E)=\frac{\mu_{0} E+v_{\text {peak }}\left(E / E_{C}\right)^{n_{1}}}{1+n_{2}\left(E / E_{C}\right)^{n_{3}}+\left(E / E_{C}\right)^{n_{4}}} .
$$

where $v_{\text {peak }}$ is the electron peak velocity and $E_{C}$ is the critical electric field where electron peak velocity occurs. $n_{4}$ is the additional a fitting parameter. However, we found that there is a relation between $n_{3}$ and $n_{4}$ fitting parameters, where $n_{3}$ should be bigger with very little difference than $n_{4}$. To consider it, if we assume that $n_{3}=n_{4}+b$, where $n_{3}, n_{4}$, and $b$ are positive numbers

$$
v(E)=\frac{\mu_{0} E+v_{\text {peak }}\left(E / E_{C}\right)^{n_{1}}}{1+n_{2}\left(E / E_{C}\right)^{n_{4}+b}+\left(E / E_{C}\right)^{n_{4}}} .
$$

Then, (3) transform into the following equation:

$$
v(E)=\frac{\mu_{0} E+v_{\text {peak }}\left(E / E_{C}\right)^{n_{1}}}{1+\left(E / E_{C}\right)^{n_{4}} \times\left(1+n_{2}\left(E / E_{C}\right)^{b}\right)} .
$$

Also, we used (5) as a fitting procedure for other materials with NDR behavior, and $b$ parameter shows a very small deviation. Our all tryouts with different materials show that $b$ parameter can be used as $0.05 \pm 0.01$. When (5) is fitted to the experimental data, the reasonable agreement between the experimental data and the model is obtained. This expression gives us that $v_{\text {peak }}$ parameter values of $951 \mathrm{~N}$ and $951 \mathrm{Y}$ are $2.06 \times 10^{7}$ and $1.44 \times 10^{7} \mathrm{~cm} / \mathrm{s}$, respectively. These values are very close to our experimental data. According to these results, the expression given in (5) can more satisfactory describe the $v_{d}-E$ characteristics with the NDR effect in GaN-based heterostructures. Another notable result in Tables III and IV is that $n_{1}$ and $n_{2}$ parameters of (5) are the same for two samples and $b$ parameter varies between 0.04 and 0.06 . It could be considered in further studies.

Therefore, a new field-dependent mobility model obtained from (5) has been developed which is given by

$$
\mu=\frac{\mu_{0}+v_{\text {peak }} \frac{E^{n_{1}-1}}{E_{C}^{n_{1}}}}{1+\left(E / E_{C}\right)^{n_{4}} \times\left(1+n_{2}\left(E / E_{C}\right)^{b}\right)} .
$$

\section{CONCLUSION}

The nanosecond-pulsed $I-V$ measurements for $\mathrm{Al}_{0.3}$ $\mathrm{Ga}_{0.7} \mathrm{~N} / \mathrm{AlN} / \mathrm{GaN}$ heterostructures without and with in situ $\mathrm{Si}_{3} \mathrm{~N}_{4}$ passivation layer are performed at $77 \mathrm{~K}$ and up to $475-\mathrm{kV} / \mathrm{cm}$ electric field values owing to smaller lengths of the sample and the protection maintained by the $\mathrm{Si}_{3} \mathrm{~N}_{4}$ surface passivation layer. These measurements revealed the electron drift velocity data as a function of electric field for the wide range. The effect of in situ $\mathrm{Si}_{3} \mathrm{~N}_{4}$ passivation on $v_{d}-E$ characteristics in $\mathrm{Al}_{0.3} \mathrm{Ga}_{0.7} \mathrm{~N} / \mathrm{AlN} / \mathrm{GaN}$ heterostructures was also investigated. After passivation, peak velocity reduction from $2.01 \times 10^{7}$ to $1.39 \times 10^{7} \mathrm{~cm} / \mathrm{s}$ was observed. As another result of this paper, a fitting expression describing the $v_{d}-E$ characteristics for $\mathrm{AlGaN} / \mathrm{AlN} / \mathrm{GaN}$ heterostructures has been 
derived. It can explain the experimental $v_{d}-E$ characteristics with NDR effect at large electric fields up to $475 \mathrm{kV} / \mathrm{cm}$. This expression can be used in the device simulators to design better GaN-based semiconductor structures and to obtain more reliable results.

\section{REFERENCES}

[1] R. J. Trew, G. L. Bilbro, W. Kuang, Y. Liu, and H. Yin, "Microwave AlGaN/GaN HFETS," IEEE Microw. Mag., vol. 6, no. 1, pp. 56-66, Mar. 2005, doi: 10.1109/MMW.2005.1417998.

[2] U. K. Mishra, L. Shen, T. E. Kazior, and Y.-F. Wu, "GaN-based RF power devices and amplifiers," Proc. IEEE, vol. 96, no. 2, pp. 287-305, Feb. 2008, doi: 10.1109/JPROC.2007.911060.

[3] T. Yamasaki et al., "A 68\% efficiency, C-band 100W GaN power amplifier for space applications," in IEEE MTT-S Int. Microw. Symp. Dig., May 2010, pp. 1384-1387, doi: 10.1109/MWSYM.2010.5517228.

[4] M. Levinshtein, S. L. Rumyantsev, and M. S. Shur, Properties of Advanced Semiconductor Materials. New York, NY, USA: Wiley, 2001.

[5] Y.-F. Wu et al., "Very high breakdown voltage and large transconductance realized on GaN heterojunction field effect transistors," Appl. Phys. Lett., vol. 69, no. 9, p. 1438, 1996, doi: 10.1063/1.117607.

[6] S. Maroldt et al., "Gate-recessed $\mathrm{AlGaN} / \mathrm{GaN}$ based enhancementmode high electron mobility transistors for high frequency operation," Jpn. J. Appl. Phys., vol. 48, no. 4S, p. 04C083, 2009, doi: 10.1143/ JJAP.48.04C083

[7] A. Asgari, M. Kalafi, and L. Faraone, "Effects of partially occupied subbands on two-dimensional electron mobility in $\mathrm{Al}_{x} \mathrm{Ga}_{1-x} \mathrm{~N} / \mathrm{GaN}$ heterostructures," J. Appl. Phys., vol. 95, no. 3, p. 1185, 2004, doi: 10.1063/ 1.1635654.

[8] M. Higashiwaki, T. Mimura, and T. Matsui, "GaN-based FETs using Cat-CVD SiN passivation for millimeter-wave applications," Thin Solid Films, vol. 516, no. 5, pp. 548-552, 2008, doi: 10.1016/J.TSF.2007.06.090.

[9] R. Vetury, N. Q. Zhang, S. Keller, and U. K. Mishra, "The impact of surface states on the DC and RF characteristics of AlGaN/GaN HFETs," IEEE Trans. Electron Devices, vol. 48, no. 3, pp. 560-566, Mar. 2001, doi: $10.1109 / 16.906451$

[10] Y. Ohno, T. Nakao, S. Kishimoto, K. Maezawa, and T. Mizutani, "Effects of surface passivation on breakdown of $\mathrm{AlGaN} / \mathrm{GaN}$ high-electronmobility transistors," Appl. Phys. Lett., vol. 84, no. 12, pp. 2184-2186, 2004, doi: 10.1063/1.1687983.

[11] B. M. Green, K. K. Chu, E. M. Chumbes, J. A. Smart, J. R. Shealy, and L. F. Eastman, "The effect of surface passivation on the microwave characteristics of undoped AlGaN/GaN HEMTs," IEEE Electron Device Lett., vol. 21, no. 6, pp. 268-270, Jun. 2000, doi: 10.1109/55.843146.

[12] J. M. Barker, D. K. Ferry, D. D. Koleske, and R. J. Shul, "Bulk GaN and AlGaN/GaN heterostructure drift velocity measurements and comparison to theoretical models," J. Appl. Phys., vol. 97, no. 6, p. 063705, 2005, doi: $10.1063 / 1.1854724$

[13] F. Schwierz, "Graphene transistors," Nature Nanotechnol., vol. 5, no. 7, pp. 487-496, May 2010, doi: 10.1038/nnano.2010.89.

[14] T. Palacios and U. K. Mishra, "GaN-based transistors for high-frequency applications," in Comprehensive Semiconductor Science and Technology, P. Bhattacharya, R. Fornari H. Kamimura, Eds. Amsterdam, The Netherlands: Elsevier, 2011, pp. 242-298.

[15] M. Wraback et al., "Time-resolved electroabsorption measurement of the electron velocity-field characteristic in GaN," Appl. Phys. Lett., vol. 76, no. 9 , p. 1155 , 2000, doi: $10.1063 / 1.125968$

[16] L. Ardaravičius et al., "Electron drift velocity in AlGaN/GaN channel at high electric fields," Appl. Phys. Lett., vol. 83, no. 19, pp. 4038-4040, 2003, doi: 10.1063/1.1626258.

[17] T. H. Yu and K. F. Brennan, "Monte Carlo calculation of twodimensional electron dynamics in GaN-AlGaN heterostructures," J. Appl. Phys., vol. 91, no. 6, pp. 3730-3736, 2002, doi: 10.1063/ 1.1448889 .

[18] M. Singh and J. Singh, "Design of high electron mobility devices with composite nitride channels," J. Appl. Phys., vol. 94, no. 4, pp. 2498-2506, 2003, doi: 10.1063/1.1594272.

[19] M. Farahmand et al., "Monte Carlo simulation of electron transport in the III-nitride wurtzite phase materials system: Binaries and ternaries," IEEE Trans. Electron Devices, vol. 48, no. 3, pp. 535-542, Mar. 2001, doi: $10.1109 / 16.906448$.
[20] L. Ardaravičius et al., "Comparative analysis of hot-electron transport in AlGaN/GaN and AlGaN/AlN/GaN 2DEG channels," Phys. Status Solidi A, vol. 202, no. 5, pp. 808-811, 2005, doi: 10.1002/ pssa.200461618.

[21] B. A. Danilchenko, N. A. Tripachko, A. E. Belyaev, S. A. Vitusevich, H. Hardtdegen, and H. Lüth, "High-field quasiballistic transport in AlGaN/GaN heterostructures," Appl. Phys. Lett., vol. 104, no. 7, p. 072105, 2014, doi: 10.1063/1.48662.81.

[22] L. Ardaravičius et al., "Hot-electron drift velocity in AlGaN/AlN/AlGaN/GaN camelback channel," Semicond. Sci. Technol., vol. 27, no. 12, p. 122001, 2012, doi: 10.1088/0268-1242/27/12/122001.

[23] L. Guo et al., "Effects of light illumination on electron velocity of $\mathrm{AlGaN} / \mathrm{GaN}$ heterostructures under high electric field," Appl. Phys. Lett., vol. 105 , no. 24, p. 242104, 2014, doi: 10.1063/1.4904418.

[24] J. B. Gunn, "Microwave oscillations of current in III-V semiconductors," Solid State Commun., vol. 1, no. 14, pp. 88-91, 1963, doi: 10.1016/ 0038-1098(63)90041-3

[25] L. Shen et al., "Negative differential resistance in the $I-V$ curves of $\mathrm{Al}_{2} \mathrm{O}_{3} / \mathrm{AlGaN} / \mathrm{GaN}$ MIS structures," $R S C A d v$, vol. 6, no. 7, pp. 5671-5676, 2016, doi: 10.1039/C5RA22356C.

[26] Z. C. Huang, R. Goldberg, J. C. Chen, Y. Zheng, D. B. Mott, and P. Shu, "Direct observation of transferred-electron effect in GaN," Appl. Phys. Lett., vol. 67, no. 19, pp. 2825-2826, 1995, doi: 10.1063/1.114797.

[27] C. Bayram, Z. Vashaei, and M. Razeghi, "Reliability in roomtemperature negative differential resistance characteristics of lowaluminum content $\mathrm{AlGaN} / \mathrm{GaN}$ double-barrier resonant tunneling diodes," Appl. Phys. Lett., vol. 97, no. 18, p. 181109, 2010, doi: 10.1063/ 1.3515418 .

[28] N. Balkan, M. C. Arikan, S. Gokden, V. Tilak, B. Schaff, and R. J. Shealy, "Energy and momentum relaxation of hot electrons in GaN/AlGaN," J. Phys. Condens. Matter, vol. 14, no. 13, pp. 3457-3468, 2002, doi: 10.1088/0953-8984/14/13/305.

[29] B. K. Ridley, W. J. Schaff, and L. F. Eastman, "Hot-phononinduced velocity saturation in GaN," J. Appl. Phys., vol. 96, no. 3, pp. 1499-1502, Aug. 2004, doi: 10.1063/1.1762999.

[30] S. Ardali et al., "The variation of temperature-dependent carrier concentration and mobility in AlGaN/AlN/GaN heterostructure with $\mathrm{SiN}$ passivation," Phys. Status Solidi B, vol. 252, no. 9, pp. 1960-1965, 2015, doi: 10.1002/pssb.201552135.

[31] L. Guo et al., "Hot electron induced non-saturation current behavior at high electric field in InAlN/GaN heterostructures with ultrathin barrier," Sci. Rep., vol. 6, p. 37415, Nov. 2016, doi: 10.1038/srep37415.

[32] L. Ardaravičius et al., "Hot-electron transport in 4H-SiC," Appl. Phys. Lett., vol. 86, no. 2, pp. 022107, 2005, doi: 10.1063/1.1851001.

[33] J. Liberis et al., "Hot-phonon lifetime in $\mathrm{Al}_{0.23} \mathrm{Ga}_{0.77} \mathrm{~N} / \mathrm{GaN}$ channels," Semicond. Sci. Technol., vol. 29, no. 4, p. 045018, 2014, doi: 10.1088/0268-1242/29/4/045018

[34] J. M. Barker, D. K. Ferry, S. M. Goodnick, D. D. Koleske, A. Allerman, and R. J. Shul, "High field transport in GaN/AlGaN heterostructures," J. Vac. Sci. J. Vac. Sci. Technol. B, Microelectron. Process. Phenom., vol. 3, no. 4, pp. 2045-2050, 2004, doi: 10.1116/1.1775199.

[35] A. Matulionis and H. Morkoç, "Hot phonons in InAlN/AlN/GaN heterostructure 2DEG channels," Proc. SPIE, vol. 7216, p. 721608, Feb. 2009, doi: 10.1117/12.802341.

[36] A. Matulionis, J. Liberis, I. Matulioniene, M. Ramonas, and E. Sermuksnis, "Ultrafast removal of LO-mode heat from a GaN-based two-dimensional channel," Proc. IEEE, vol. 98, no. 7, pp. 1118-1126, Jul. 2010, doi: 10.1109/JPROC.2009.2029877.

[37] F. Schwierz, "An electron mobility model for wurtzite GaN," SolidState Electron., vol. 49, no. 6, pp. 889-895, 2005, doi: 10.1016/ j.sse.2005.03.006.

[38] J. Kolnik, I. Oguzman, K. E. Brennan, R. Wang, P. Ruden, and Y. Wang, "Electronic transport studies of bulk zincblende and wurtzite phases of GaN based on an ensemble Monte Carlo calculation including a full zone band structure," J. Appl. Phys., vol. 78, pp. 1033-1038, 1995, doi: $10.1063 / 1.360405$.

[39] S. Krishnamurthy, M. van Schilfgaarde, A. Sher, and A. B. Chen, "Bandstructure effect on high-field transport in GaN and GaAlN," Appl. Phys. Lett., vol. 71, no. 14, pp. 1999-2001, 1997, doi: 10.1063/1.119767.

[40] R. Brazis and R. Raguotis, "Additional phonon modes and close satellite valleys crucialfor electron transport in hexagonal gallium nitride," Appl. Phys. Lett., vol. 85, no. 4, pp. 609-611, 2004, doi: 10.1063/1.1776622.

[41] J. T. Lü and J. C. Cao, "Terahertz generation and chaotic dynamics in GaN NDR diode," Semicond. Sci. Technol., vol. 19, no. 3, pp. 451-456, 2004, doi: 10.1088/0268-1242/19/3/028. 
[42] M. Piccardo et al., "Determination of the first satellite valley energy in the conduction band of wurtzite GaN by near-band-gap photoemission spectroscopy," Phys. Rev. B, Condens. Matter, vol. 89, no. 23, p. 235124, 2014, doi: 10.1103/PhysRevB.89.235124.

[43] O. Katz, A. Horn, G. Bahir, and J. Salzman, "Electron mobility in an $\mathrm{AlGaN} / \mathrm{GaN}$ two-dimensional electron gas. I. Carrier concentration dependent mobility," IEEE Trans. Electron Devices, vol. 50, no. 10, pp. 2002-2008, Oct. 2003, doi: 10.1109/TED.2003.816103.

[44] W. S. Tan, P. A. Houston, P. J. Parbrook, G. Hill, and R. J. Airey, "Comparison of different surface passivation dielectrics in AlGaN/GaN heterostructure field-effect transistors," J. Phys. D, Appl. Phys., vol. 35, no. 7, pp. 595-598, 2002, doi: 10.1088/0022-3727/35/7/304.

[45] D. M. Chang and J. L. Moll, "Direct observation of the drift velocity as a function of the electric field in gallium arsenide," Appl. Phys. Lett., vol. 9, no. 8, pp. 283-285, 1966, doi: 10.1063/1.1754751.

[46] R. Yahyazadeh, A. Asgari, and M. Kalafi, "The effects of depletion layer on negative differential conductivity in AlGaN/GaN high electron mobility transistor," Physica E, Low-Dimensional Syst. Nanostruct., vol. 33, no. 1, pp. 77-82, 2006, doi: 10.1016/j.physe.2005.11.011.

[47] B. K. Ridley and T. B. Watkins, "The dependence of capture rate on electric field and the possibility of negative resistance in semiconductors," Proc. Phys. Soc., vol. 78, no. 5, pp. 710-715, 1961, doi: 10.1088/0370$1328 / 78 / 5 / 309$

[48] S. Vitanov et al., "Physics-based modeling of GaN HEMTs," IEEE Trans. Electron Devices, vol. 59, no. 3, pp. 685-693, Mar. 2012, doi: 10. 1109/TED.2011.2179118.

[49] S. Selberherr, Analysis and Simulation of Semiconductor Devices. New York, NY, USA: Springer-Verlag, 1984.

[50] D. M. Caughey and R. E. Thomas, "Carrier mobilities in silicon empirically related to doping and field," Proc. IEEE, vol. 52, no. 12, pp. 2192-2193, Dec. 1967, doi: 10.1109/PROC.1967.6123.

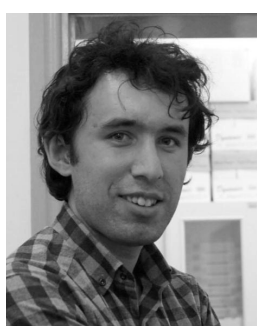

Gökhan Atmaca was born in Ankara, Turkey. He received the B.Sc. degree from the Department of Physics, Gazi University, Ankara, in 2010, and the M.Sc. and Ph.D. degrees in physics from Gazi University in 2012 and 2018, respectively.

His current research interests include electron and magnetotransport properties, device modeling, and transfer and breakdown characteristics of III-V group semiconductor materials.

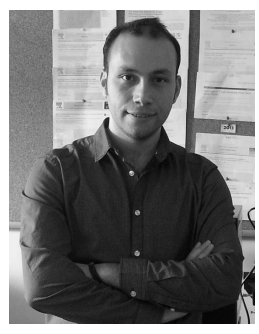

Polat Narin was born in Ankara, Turkey, in 1989. $\mathrm{He}$ received the B.Sc. and M.Sc. degrees in physics from Gazi University, Ankara, in 2011 and 2015 , respectively, where he is currently pursuing the Ph.D. degree with the Department of Physics, with a focus on crystal growth, electrical, structural, and optical properties of III-Nitrides and $\mathrm{ZnO}$ thin films.

His current research interests include numerical calculations of low-dimensional semiconductor materials.

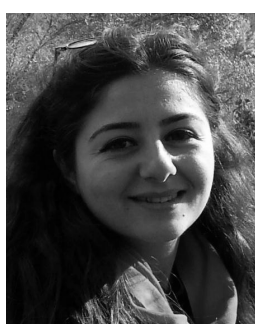

Ece Kutlu received the B.Sc. and M.Sc. degrees from the Physics Department, Faculty of Science, Gazi University, Ankara, Turkey, in 2013 and 2016 , respectively. She is currently pursuing the Ph.D. degree with the Department of Energy Systems Engineering, Faculty of Engineering and Natural Sciences, Ankara Yıldırım Beyazıt University, Ankara.

Her current research interests include electrical, structural, and optical properties of wide bandgap semiconductors.

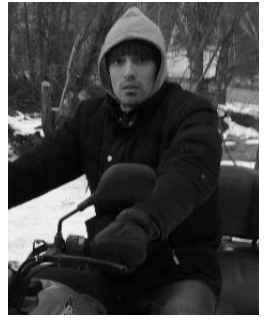

Timur Valerevich Malin was born in 1984. He received the Degree in physical electronics from the Faculty of Radio Engineering Electronics and Physics, Novosibirsk State Technical University, Novosibirsk, Russia, in 2006.

Since 2009, he has been a Senior Engineer with the Laboratory No. 37 Molecular-Beam Epitaxy of Semiconductor Compounds A3B5, Rzhanov Institute of Semiconductor Physics, Siberian Branch of Russian Academy of Sciences, Novosibirsk.

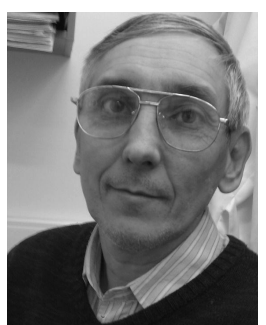

Vladimir G. Mansurov received the M.S. degree from Novosibirsk State University, Novosibirsk, Russia, in 1985, and the Ph.D. degree from the Rzhanov Institute of Semiconductor Physics, Siberian Branch of Russian Academy of Sciences, Novosibirsk, in 2000.

$\mathrm{He}$ is currently a Senior Scientific Researcher with the Rzhanov Institute of Semiconductor Physics, Siberian Branch of Russian Academy of Sciences.

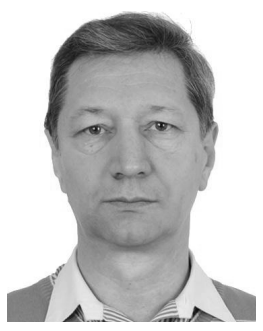

Konstantin Sergeevich Zhuravlev received the M.S. degree from the Novosibirsk Institute of Electrical Engineering, Novosibirsk, Russia, in 1979, and the D.Sc. degree from the Rzhanov Institute of Semiconductor Physics, Siberian Branch of Russian Academy of Sciences, Novosibirsk, in 2006.

$\mathrm{He}$ is currently a Leading Research Fellow with the Rzhanov Institute of Semiconductor Physics, Siberian Branch of Russian Academy of Sciences.

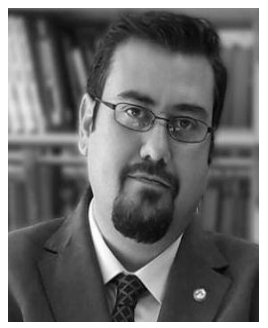

Sefer Bora Lișesivdin (SM'15) was born in Ankara, Turkey. He received the B.Sc. degree from the Department of Physics Engineering, Hacettepe University, Ankara, in 2003, and the M.Sc. degree in advanced technologies and the Ph.D. degree in physics from Gazi University, Ankara, in 2005 and 2008, respectively.

$\mathrm{He}$ is currently an Associate Professor with the Department of Physics, Gazi University.

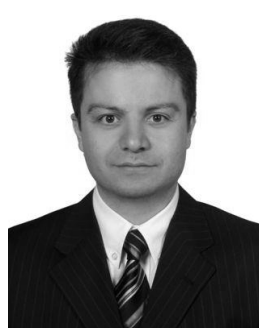

Ekmel Özbay (M'98) received the M.S. and Ph.D. degrees in electrical engineering from Stanford University, Stanford, CA, USA, in 1989 and 1992, respectively.

In 1995, he joined Bilkent University, Ankara, Turkey, where he is currently a Full Professor with the Department of Electrical and Electronics Engineering and the Department of Physics, and also the Founding Director of the Nanotechnology Research Center. 